Disponível em

http://www.anpad.org.br/rac

RAC, Rio de Janeiro, v. 19, n. 6, art. 2, pp. 696-711, Nov./Dez. 2015

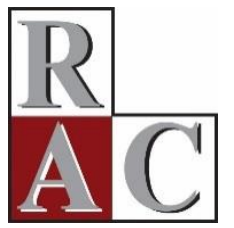

\title{
Teoria do Equilíbrio Pontuado nas Políticas Públicas Brasileiras: O Caso do Ceará
}

\author{
Punctuated Equilibrium Theory in Brazilian Public Policy: The Case of Ceará
}




\title{
Resumo
}

Este artigo faz uma análise do processo de decisão orçamental dos municípios do Estado do Ceará. Através deste estudo, procura-se perceber em que medida a distribuição dos orçamentos aos governos locais sofrem (ou não) variações. Já em um segundo momento, tenta-se depreender quais as receitas de cada um dos municípios (as variáveis independentes) que melhor descrevem e auxiliam a opção política de investimento local (esta será a variável dependente). Considerando o período de 2006 a 2010 e fazendo uso de um desenho de pesquisa de tipo transversal, conclui-se que nos governos locais do Ceará o investimento público apresenta períodos de estabilidade seguido por períodos de grande alteração dos orçamentos - confirmando a hipótese de pesquisa. Estas conclusões confirmam os pressupostos da teoria do equilíbrio pontuado. Conclui-se igualmente que o investimento público que vem sendo realizado é dependente das transferências que a União faz para os governos locais do Estado do Ceará e das receitas de capital. Face a estas condições, é pertinente equacionar até que nível e grau o endividamento pode ocorrer em virtude da escassez cada vez maior do financiamento público.

Palavras-chave: políticas públicas; teoria do equilíbrio pontuado; investimento público; Ceará.

\begin{abstract}
This research aims to analyze the budget decision process in Ceará municipalities in order to understand in which way budget distributions change (or not) during the research period under consideration. This research also aims to understand which revenues (the independent variables) of each municipality better explain the political choices for local government investments (the dependent variable). Making use of data from 2006 to 2010 and using a cross-sectional research design, the study concludes a stability in local government investments periods of stress where such investments have both positive and negative significant fluctuations - confirming our working hypothesis. These results confirm punctuated Equilibrium Theory assumptions and also find that local government public investment is dependent on money transfers from the central government and also from capital revenues. Thus, it is important to question to what degree public indebtedness should be allowed, due to a scarcity of public funds.
\end{abstract}

Key words: public policy; punctuated equilibrium theory; public investment; Ceará. 


\section{Introdução}

O estudo do processo de decisão orçamental e a concomitante priorização das necessidades é um tema que tem sido objeto de análise por vários acadêmicos (Birkland, 2011; Jordan, 2003; Robinson, Caver, Meier, \& O'Toole, 2004). Assim, coloca-se a seguinte questão de pesquisa: Qual a relação existente entre a decisão para a distribuição do orçamento dos municípios e a tomada de decisão no Governo Local? Com esta questão de partida procura-se, num primeiro momento, descrever a regularidade do fenômeno (Blaikie, 2000), ou seja, pretende-se perceber em que medida a distribuição dos orçamentos aos governos locais sofrem (ou não) variações. Pretende-se igualmente descrever, e já num segundo momento, quais as receitas de cada um dos municípios (as variáveis independentes) que melhor descrevem e auxiliam a opção política de investimento (a variável dependente). A questão de partida e objetivo de estudo tornam-se pertinentes para o campo de pesquisa da Administração e Políticas Públicas, como será comprovado com base na teoria do equilíbrio pontuado.

Por política pública entendemos como sendo constituída por toda e qualquer decisão das autoridades governativas, e onde se inclui a sua execução (Denhardt, 2000). Pese embora assumida como toda e qualquer decisão [por decisão entende-se como a escolha de uma via de ação em particular (Simon, 1982), as políticas públicas, enquanto processo político, passam, em norma, por uma sequência de fases. Como referido, elas ocorrem com o surgimento ou emergência de um assunto que entrará para a discussão política através da agenda estabelecida e na qual os tomadores de decisão terão de escolher uma entre as possíveis alternativas que se colocam (Birkland, 2011). Depois de decidida a política pública, e ainda segundo o autor, terão início as fases de implementação e avaliação.

Face ao descrito, assume-se que a importância para a escolha deste tema resulta dos acontecimentos econômicos que vêm acontecendo em termos globais desde 2008. Desde então, e como refere Pollitt (2012), a crise econômica colocou os orçamentos públicos nacionais e locais sob escrutínio elevado em razão da ainda maior escassez de recursos disponíveis para promover as políticas públicas. Nesta senda avança o autor que os investimentos devem ser devidamente esmiuçados a ponto de se perceber política e efetivamente quais as benfeitorias que dali advirão. A margem de erro da decisão para a adoção de determinada política, quer em relação às prioridades sociais e políticas constatadas, quer em relação às mais-valias sociais que dali resultarão é, na verdade, reduzida.

Neste contexto é igualmente importante que a evolução prática seja suportada pela evolução acadêmica no que concerne à explicação de determinados fenômenos. Neste aspecto em particular, surgiu a teoria do equilíbrio pontuado que, segundo os seus iniciadores (Jones \& Baumgartner, 2005; True, Jones, \& Baumgartner, 2007), procura analisar a questão que aqui se propõe apurar - daí que a teoria do equilíbrio pontuado surja como enquadramento teórico para esta investigação. Os autores da teoria do equilíbrio pontuado assumem que os processos de decisão política para a afetação dos recursos públicos escassos têm sido caracterizados por uma grande estabilidade e incrementalismo (True et al., 2007). Contudo, essas decisões apresentam variações em relação ao investimento público feito em determinadas áreas sociais. O objetivo da teoria do equilíbrio pontuado centra-se, então, na verificação e entendimento das decisões e razões para a tomada de decisão sobre quais políticas públicas serão adotadas e executadas.

Segundo os autores, a teoria do equilíbrio pontuado foi criada e tem sido desenvolvida desde a década de 90, em especial nos Estados Unidos da América. Vários estudos foram, entretanto, realizados, sendo que é usualmente a realidade norte-americana a que é geralmente focada. True, Jones e Baumgartner (2007) sugerem que é necessário que se conheça se esta teoria é capaz de explicar o mesmo fenômeno para além da realidade da América do Norte, cujo sistema é per se muito particular.

Esta necessidade da teoria do equilíbrio pontuado e a importância e pertinência do tema para o contexto nacional justificam a escolha do Brasil para realizar a análise. Segundo Jones e Baumgartner (2005), é necessário que a teoria seja aplicada em outros contextos para além dos países anglo-saxônicos, daí a preferência pelo Brasil, uma vez que este país apresenta similitudes em relação à organização política e administrativa - Federação, Estados e governos locais. Por tudo isto, a opção para a aplicação 
da teoria do equilíbrio pontuado no contexto nacional brasileiro torna-se justificado. Acrescenta-se que este estudo permitirá comprovar, ou não, a teoria do equilíbrio pontuado para além dos países anglosaxônicos.

O trabalho começa por apresentar o enquadramento teórico, nomeadamente com a caracterização do método incremental que foi complementado pela teoria do equilíbrio pontuado. Depois de caracterizar a teoria do equilíbrio pontuado, são apresentados alguns estudos realizados e respectivos resultados. Em seguida, expõe-se a metodologia na qual se procura balizar as escolhas de investigação. $\mathrm{Na}$ continuação, são apresentados os resultados e discutidos os mesmos à luz do enquadramento teórico eleito, terminando o trabalho com uma reflexão final.

\section{Teorias e Métodos de Decisão Política na Adoção de Políticas Públicas}

As teorias e métodos de decisão no processo de tomada de decisão na administração pública têm evoluído. Se em um primeiro momento o método incremental prevaleceu na explicação deste fenômeno (Robinson et al., 2004), mais tarde veio a ser complementado pela teoria do equilíbrio pontuado (Jones \& Baumgartner, 2005). Os dois modelos, embora estando aparentemente distanciados, acabam por se complementar na análise.

\section{O método incremental para a afetação de recursos públicos}

O método incremental foi utilizado durante muitos anos como modelo teórico explicativo para a tomada de decisão sobre as políticas públicas a serem adotadas. Consequentemente, as decisões acerca dos recursos a serem utilizados na prossecução das decisões políticas seguiam este método (Jordan, 2003; Robinson et al., 2004).

Neste método verifica-se que as decisões são tomadas sobre a marginalidade das mudanças que possam ocorrer de um ano para o outro, logo é assumido que as decisões dos anos transatos eram aceitas sem ressalvas (John \& Margetts, 2003; Jones \& Baumgartner, 2005; Jones, Sulkin, \& Larsen, 2003). Assim, pode-se afirmar que as mudanças nas políticas são basicamente pontuais e marcadamente modestas, permitindo, deste modo, aos políticos, o necessário aprendizado sobre as políticas públicas que funcionam e que não funcionam (Birkland, 2011). Para este efeito, a rotinização dos processos para a coleta de informação e posterior tomada de decisão é uma das grandes vantagens, embora não seja a única. Para os decisores políticos, há mais três razões para a sua utilização, a saber: a facilidade na verificação dos erros do passado; o desejo dos decisores de manterem as expectativas num ambiente de grande incerteza e complexidade; e a interação institucional que fará com que haja conflito, apenas evitado através do compromisso dos seus participantes (Jones \& Baumgartner, 2005). Contudo, para Jones e Baumgartner (2005), este método não explica como os decisores alcançam estes ajustamentos, principalmente quando concluem que a tomada de decisão orçamental não é incremental, como inicialmente proposto.

\section{A teoria do equilíbrio pontuado como modelo alternativo para a afetação de recursos}

Auxiliando os princípios do anterior método de explicação de tomada de decisão política para a adoção de políticas públicas, surgiu na década de 90 a teoria do equilíbrio pontuado proposta por Jones e Baumgartner (2005). Segundo estes autores, a teoria do equilíbrio pontuado não é em si um modelo de decisão - como é o método incremental. Esta teoria, para além da questão decisória, contempla o processamento da informação considerada importante pelos decisores - concentrando-se mais nos impactos que os bens e serviços públicos têm sobre os usuários (os outcomes), em detrimento dos produtos ou serviços prestados per se (os outputs). 
Os autores partem da premissa de que o incrementalismo implica um ajustamento na tomada de decisão daquilo que foi decidido no ano anterior - "a decisão de hoje é um ajustamento da decisão de ontem" (Jones \& Baumgartner, 2005, p. 326). Assim sendo, existe um pressuposto de equidade na distribuição do orçamento entre as várias agências governamentais - se no ano $n$, à agência $X$, foi atribuído um montante financeiro diminuto, compensar-se-á a mesma no ano $n+l$ com o diferencial que lhe deveria ter sido atribuído no ano transato. Na sequência deste pressuposto, defendem igualmente que as políticas de distribuição do dinheiro público seguem uma tendência estável num longo período (Birkland, 2011). Contudo, existem momentos de mudança abrupta, quer na opção sobre as políticas públicas que devem ser privilegiadas, quer também nos montantes envolvidos no investimento nessas mesmas políticas, daí que estas decisões possam não ser incrementais.

A teoria do equilíbrio pontuado surge como um complemento explicativo do método incremental. Os autores assumem que as decisões orçamentais num determinado ano (n) podem resultar em decisões que diferem grandemente das decisões de anos anteriores (n-1, n-2, n-3...) - não sendo por isso decisões incrementais. E essas alterações não podem ser simplesmente explicadas pela ação dos partidos políticos, por razões econômicas ou pela opinião pública (Jordan, 2003). Relevante é o fato de que o método incremental se baseava na concepção do homo economicus proposto pelos clássicos. Segundo os clássicos, este tipo de homem procura a melhor das alternativas, o máximo lucro e o melhor preço. Jones e Baumgartner (2005) chegaram a esta conclusão através do seguinte entendimento: se a tomada de decisão orçamental fosse incremental (na qual pouco, ou nada, se alteraria de um ano para o outro), assistir-se-ia a uma distribuição normal na frequência das mudanças percentuais orçamentais - o que se espera a partir da adoção deste método. Declinam contudo desta hipótese, porque constataram que a distribuição de frequência nas mudanças orçamentais aponta para uma distribuição leptocúrtica. Este tipo de distribuição é um "indicador primário da desproporcionalidade no processo de escolha" (Jones \& Baumgartner, 2005, p. 336).

Segundo os autores, a distribuição leptocúrtica é muito semelhante à distribuição proposta por Pareto, ou seja, a elevada tendência junto do zero nas mudanças ocorridas indicia um programa de estabilidade - a maioria da variação nos orçamentos é diminuta, centrando-se assim no indicativo zero. Contudo, embora exista uma certa estabilidade, constata-se por vezes um grau elevado de alterações na distribuição do orçamento. Tal fato tem sido verificado por vários estudos e que de imediato passamos a analisar.

\section{Estudos Realizados e Hipótese de Trabalho}

Para Jones e Baumgartner (2005), a variável independente informação (cuja variável dependente é a tomada de decisão) é primordial no entendimento da teoria do equilíbrio pontuado. Existem, portanto, duas perspectivas quanto à disponibilidade da informação: a primeira é a de que a informação não está disponível a quem dela precisa para tomar uma decisão; e a segunda é de que a informação está disponível, o que difere é o seu tratamento - esta última perspectiva é adotada pelos investigadores. Pode-se então concluir que, se ocorrer uma distribuição normal na tomada de decisão orçamental, assume-se que existe uma atualização proporcional da informação - característica do método incremental. Caso contrário, se assistirmos a uma distribuição de frequência de tipo leptocúrtica, é porque houve uma desproporcionalidade na atualização da informação que levou a uma variação no processo de tomada de decisão orçamental.

Face a este raciocínio de relação entre informação e tomada de decisão, os autores adotam o conceito de homem administrativo proposto por Simon (1982), em detrimento do homo economicus proposto pelos clássicos - este procura a melhor das alternativas, o máximo lucro e o melhor preço. Pelo contrário, Simon (1982), ao propor o conceito de homem administrativo, defende a racionalidade limitada dos decisores, pelo simples fato de que não é possível ao ser humano ser detentor de toda a informação sobre a envolvente, seja ela geral ou específica. Daí que o homem administrativo, face à sua racionalidade limitada, procurará a alternativa suficientemente boa, o lucro suficiente e o preço justo. 
Existe, assim, uma alteração do entendimento de como a informação é processada e disponibilizada, assim como uma alteração das implicações na tomada de decisão e, consequentemente, nos objetivos que daí resultarão.

Porém, o problema central para Jones e Baumgartner (2005) é o de saber que fatores levam os decisores a dar prioridade à determinada informação para a tomada de decisão. Esta surge, porque se a distribuição não é normal, então o método incremental não consegue explicar em que medida ocorreram essas alterações na ponderação da informação. Os autores explicam as diferentes decisões orçamentais com os custos associados à decisão. Tais custos podem gerar uma crispação organizacional. São quatro, segundo eles, os custos associados à tomada de decisão: custos de decisão (são custos em que o ator incorre para chegar a um entendimento e que poderão se dividir em: custos de barganha e custos institucionais); custos de transação (são os custos decorrentes do acordo celebrado); custos de informação (são os custos de indagação de informação relevante para a tomada de decisão); e custos cognitivos (firmam-se na capacidade limitada de processo da organização - porquanto é a organização) formada por seres humanos - seres limitados por natureza). No final, e através da consideração dos vários custos, concluem que as diferenças na tomada de decisão não são incrementais, antes são resultado dos custos associados à tomada de decisão. E completam: o aumento dos custos, para a tomada de decisão exacerba a característica leptocúrtica da distribuição.

Já Jones, Sulkin e Larsen (2003) se basearam do Equilíbrio Pontuado como teoria de suporte. Concluem, em suas indagações, que quanto maior forem os custos institucionais impostos à ação coletiva, maior será a distribuição leptocúrtica - à semelhança do estudo de Jones e Baumgartner (2005). Os autores partiram do princípio de que independentemente do insumo (o input), o que determinará o produto (o output) da decisão é a consideração dos fortes sinais (friction) que advêm do processamento de informação (o que levará a uma distribuição leptocúrtica). Outra hipótese é ignorar esses sinais (o que levará a uma distribuição normal), que têm origem nos custos de informação associados à tomada de decisão. Assim, em seus estudos socorreram-se: dos insumos de distribuição como as eleições, os mercados e novos temas considerados na agenda política; do processo político distributivo que inclui as ordens executivas, audições, etc.; e da distribuição orçamental. Concluem que, no que concerne aos insumos, a distribuição leptocúrtica era elevada, ou seja, apresentava uma distribuição não normal. Quanto ao processo político distributivo e orçamental, concluem que apresentavam, também eles, uma elevada distribuição leptocúrtica. Assim, confirmam o fato de que quando os custos institucionais são elevados, a distribuição não é normal. E avançam que, mesmo onde se depreendem custos institucionais diminutos, a tomada de decisão não é normal - ao contrário do esperado. Para mais: quanto maiores foram as mudanças nas temáticas, maiores são os desvios da tomada de decisão dos anos anteriores.

Jordan (2003) foi outra das autoras que se socorreu da teoria do equilíbrio pontuado. A autora conclui que as decisões de natureza orçamental são, na sua generalidade (não exclusivamente), estáticas. Contudo, essas decisões estáticas são interrompidas pontualmente, corroborando as conclusões de Jones e Baumgartner (2005): se a tomada de decisão orçamental fosse incremental (onde pouco, ou nada, se alteraria de um ano para o outro), assistir-se-ia a uma distribuição normal na frequência das mudanças percentuais orçamentais. A predominância das decisões estáticas justifica-se no equilíbrio e estabilidade da agenda política - "pequenas mudanças da agenda tendem a chamar menor atenção, atrai menos oposição e deixa espaço para futuras negociações" (Jordan, 2003, p. 345). Mas o que se poderá considerar de não estático ou pontuações? Para a autora, que ao contrário dos primeiros estudos onde tal fato não estaria muito claro, toda a alteração de decréscimo que tivesse $25 \%$ ou mais e toda a alteração positiva de $35 \%$ ou mais de variação de um ano para o outro seriam consideradas pontuações - e este é um contributo que será utilizado para este estudo.

No que concerne aos orçamentos locais, constata-se a existência de alterações quer negativas, quer positivas. As mudanças negativas - aquelas que implicam menores gastos orçamentais - ocorrem, por exemplo, quando a conjuntura econômico-financeira é desfavorável (pretende assim a autora concluir da relação causa-efeito entre a tomada de decisão orçamental e a conjuntura econômicofinanceira). Já as mudanças orçamentais positivas ocorrem quando há a tomada de posse do mandato tendo em vista o cumprimento das promessas eleitorais. Qualquer um destes exemplos pode fazer variar a decisão quanto ao orçamento local a ser afetado - e tal leva a um processo não incremental. Mas outros 
fatores deverão ser considerados: a competição governamental local e variáveis socioeconômicas. Isso explica por que os governos locais norte-americanos estão em constante competição para fixar o maior número de residentes adentro da sua área geográfica - que são a maior fonte de rendimentos, considerados sob a forma de impostos. Esse intento leva a modificações na alocação dos orçamentos locais para que se fixem as pessoas. Já as variáveis socioeconômicas - como a idade, profissão, etnia, etc. - exigem do decisor uma atenção constante em relação aos acontecimentos. Todos estes fatores levam a um aumento da probabilidade de ocorrência de alteração da agenda local.

Com isto, Jordan (2003) inclui no seu estudo seis funções - a saber: polícia, bombeiros, saneamento básico, parques de recreio, edifícios públicos e rodovias - compreendendo o período de 27 anos em 38 cidades consideradas de grande porte (com pelo menos 300 mil habitantes). A expectativa é a de que os serviços do dia-a-dia por ela examinados (polícia, bombeiros, saneamento básico) sejam mais estáveis do que aqueles que concernem ao encorajamento do crescimento e expansão (os gastos com parques infantis, edifícios públicos e rodovias foram os examinados) - hipótese que a conclusão do seu estudo corroborou. $\mathrm{O}$ estudo conclui que, em situação de estresse financeiro, as decisões de alocação do orçamento local favorecem mais a fixação da classe média (através da manutenção dos gastos com as funções do dia-a-dia) do que o crescimento local (decrescimento do investimento em funções não alocativas).

Para Robinson, Caver, Meier e O'Toole (2004), a teoria do equilíbrio pontuado eleva a possibilidade de fazer uma comparação entre políticas através do tempo em detrimento do espaço mesmo admitindo que tal se reveste de elevada complexidade de utilização no campo da Ciência Política. Este autor partiu das seguintes questões de investigação: qual o comportamento dos produtos nas burocracias em relação à teoria do equilíbrio pontuado? Existem duas suposições: a primeira é de que as burocracias são extremamente complexas, centralizadas e formalizadas, daí que optem pela manutenção do seu status quo, fazendo uma distribuição do tipo incremental das suas tomadas de decisão. A outra suposição é a de que os burocratas, para perpetuarem a sua existência, tomam decisões com o intento de adaptar as suas organizações à envolvente - assim não correm o risco de desatualização, logo a probabilidade de extinção motivada pelo desuso é menor. A outra das questões a ser respondida remete ao tamanho organizacional: qual é o impacto que o tamanho organizacional tem nas decisões organizacionais? Apoiando-se num universo de 1000 organizações de educação em um espaço temporal que compreendeu os anos de 1989 a 2001, as conclusões foram: a burocratização afeta a escolha entre pequenas e grandes alterações nos orçamentos das organizações. As organizações burocráticas efetuam mais frequentemente grandes e médias alterações em seus orçamentos - sejam elas positivas ou negativas. As pequenas alterações dos orçamentos são as menos utilizadas, contrariando, deste modo, as hipóteses colocadas para uma menor pontuação na tomada de decisão de alocação dos recursos. Estas conclusões fazem com que se deva "prestar maior atenção ao efeito da burocratização na realização da política educacional ao invés de se aceitar a tradicional sabedoria que a burocratização é uma barreira à mudança" (Robinson et al., 2004, p. 26).

O último trabalho foi realizado por John e Margetts (2003). Este estudo difere dos anteriores, porque foi aplicado ao governo central na Inglaterra - todos os outros versavam a comparação das alterações orçamentais em organizações norte-americanas. O espaço temporal da análise vai de 1947 a 1995. O recolhimento da informação foi preparado e comparado, através da adoção do deflator do Produto Interno Bruto (PIB) para confrontar as diferenças resultantes da taxa de inflação que ocorreram no período em consideração. Foram ainda consideradas as funções de: defesa, lei e ordem pública, transportes, educação, agricultura, saúde, habitação, indústria, assuntos econômicos e segurança social. As conclusões referem que a evolução distributiva orçamental difere de setor para setor, logo é leptocúrtica, o que significa que a variação orçamental não é uniforme.

Com esta revisão dos estudos efetuados, pode-se concluir que a totalidade dos resultados apontam para uma distribuição não incremental dos orçamentos, ou seja, existe uma grande estabilidade na distribuição dos orçamentos, sendo que ocasionalmente existe uma grande variação. Estas conclusões permitem-nos formular uma hipótese de trabalho para o estudo. Deve-se notar que tal hipótese é uma tentativa de resposta à questão de partida (Blaikie, 2000) e, a partir desse pressuposto, propõe-se a seguinte hipótese de trabalho: 
$\mathbf{H}_{1}$ : A distribuição dos orçamentos dos governos locais segue uma tendência regular, pontualmente alterada por grandes variações.

Uma vez colocada a hipótese de trabalho, verifica-se que a escolha da área a ser selecionada deve ser feita de modo criterioso. Tal intuito dá-se porque o desenvolvimento econômico faz com que os cidadãos exijam mais e melhores serviços públicos (Berry \& Berry, 2007). Acompanhando essa tendência, verifica-se que os orçamentos reagem tanto a fatores endógenos quanto a fatores exógenos, o que obriga a cautelas na escolha da área (True et al., 2007), e que a seguir se analisa e justifica.

\section{Metodologia}

Nesta parte do manuscrito, são balizadas as escolhas de investigação tendo como base a discussão teórica atrás explanada. Face ao objetivo do estudo proposto, justifica-se o desenho de pesquisa adotado e a região onde se foca a pesquisa. No final, justifica-se a escolha dos indicadores que fazem parte do modelo estatístico e as ferramentas a utilizar para o tratamento da informação coletada.

\section{Objetivo do estudo}

Como referido na Introdução, a questão de partida tende a relacionar dois conceitos centrais para a pesquisa: a tomada de decisão política e a distribuição do investimento em políticas públicas tendo como base o governo local. Esta relação tem subjacente o objetivo de, em um primeiro momento, descrever a regularidade de um fenômeno em particular (Blaikie, 2000), que no caso específico passa por descrever como tem ocorrido a distribuição do investimento público nos governos locais do Estado do Ceará, no Brasil. Não se procura, contudo, única e exclusivamente descrever o processo para o período em análise, porquanto é importante descrever em concomitância qual o fator da receita orçamentária que melhor se relaciona com essa tendência.

\section{Desenho de pesquisa e seleção do setor}

Para ir de encontro à questão de partida e respectivo objetivo de estudo, recorreu-se ao desenho de pesquisa de tipo Estudo de Painel (Blaikie, 2000; Bryman, 2004; Camões, 2012; Yin, 2009). Segundo estes autores, este desenho de pesquisa deve ser privilegiado quando se conjugam ao mesmo tempo o número de unidades comparadas e a frequência dos momentos analisados. Ressaltam os autores que esta opção é complexa, porque a análise de várias unidades ao longo de determinado tempo faz surgir tendencialmente dados que em norma não podem ser comparados em resultado da métrica utilizada ou mesmo da diferença na informação recolhida.

Mesmo com estas condicionantes, foi tomada a opção de realizar a análise nos governos locais do Estado do Ceará, no Brasil [sendo constituído por $(n=)$ 184]. Em primeiro lugar, esta opção mostrase compatível com as premissas da teoria do equilíbrio pontuado, ou seja, segundo os autores, a unidade de análise a ser empregada tanto pode ser um governo estadual, como um governo local ou uma organização pública (True et al., 2007). A segunda justificativa remete para a escolha do Estado. Neste caso em concreto, a escolha recaiu pela indagação nesta área em resultado das alterações que tem vindo a sofrer, isto é, o crescimento econômico no Ceará é em quatro vezes superior ao do Brasil, segundo dados do Instituto de Pesquisa e Estratégia Econômica do Ceará (2006, 2007, 2008, 2009, 2010). Se aliarmos o crescimento dos investimentos públicos com a necessária cautela a que a disciplina orçamental pública obriga, esta opção mostra-se correta.

Optou-se, contudo, não incluir na análise variáveis que mostrem e promovam a distinção entre os próprios governos locais porque as "regras e estruturas são (supostamente) neutras" (Birkland, 2011, p. xiii) e aqui não se pretendia tratar da questão da gestão pública, mas sim das políticas públicas. 


\section{Dados utilizados e indicadores}

Os dados utilizados correspondem ao período temporal de 5 anos - entre 2006 e 2010 - e resultam dos anuários estatísticos publicados pelo Instituto de Pesquisa e Estratégia Econômica do Ceará, o que caracteriza dados de tipo secundário (Blaikie, 2000; Bryman, 2004) - ver Tabela 1. O número de observações corresponde aos dados coletados para cada um dos governos locais; o mínimo, para o valor mais baixo constatado (medido em $\mathrm{R} \$$ ); o máximo, para o valor mais alto constatado (medido em $\mathrm{R} \$$ ); e a média entre as observações, para cada indicador (medido em $\mathrm{R} \$$ ). Esta opção não vai totalmente de encontro ao preceito de incluir em uma análise temporal de políticas públicas um período de pelo menos 10 anos (Sabatier, 2007).

Tabela 1

\section{Sumário da Estatística Descritiva}

\begin{tabular}{cccccc}
\hline Variável & Observações & Mínimo & Máximo & Média & Desvio Padrão \\
\hline INVES2006 & 184 & 86756 & 95963922 & 3864228,07 & 8417365,92 \\
INVES2007 & 181 & 89346 & 159636271 & 3580817,20 & 12347452,73 \\
INVES2008 & 177 & 248995 & 209511109 & 5905713,44 & 16914934,47 \\
INVES2009 & 184 & 110122 & 242665721 & 5126925,72 & 18334586,07 \\
INVES2010 & 180 & 633871 & 310680112 & 6885158,34 & 23301037,14 \\
RTRIBU2006 & 184 & 51885 & 375582975 & 2994890,94 & 27668834,99 \\
RTRIBU2007 & 181 & 62537 & 415491908 & 3377266,53 & 30866921,24 \\
RTRIBU2008 & 178 & 0 & 480371160 & 4089182,50 & 35993774,90 \\
RTRIBU2009 & 184 & 30812 & 532310257 & 4513339,12 & 39259365,88 \\
RTRIBU2010 & 180 & 74525 & 685995863 & 5885317,91 & 51148373,10 \\
RCONT2006 & 96 & 200 & 271996422 & 3549804,66 & 27731509,03 \\
RCONT2007 & 111 & 250 & 149868982 & 2089563,70 & 14227490,90 \\
RCONT2008 & 110 & 500 & 171505973 & 2494185,85 & 16355472,55 \\
RCONT2009 & 125 & 25 & 189249345 & 2512677,10 & 16947153,00 \\
RCONT2010 & 131 & 11 & 214015917 & 2925608,14 & 18753525,25 \\
RPATRI2006 & 183 & 613 & 48919225 & 498196,04 & 3653631,99 \\
RPATRI2007 & 111 & 250 & 149868982 & 2089563,70 & 14227490,90 \\
RPATRI2008 & 174 & 81 & 63400625 & 795756,82 & 4896340,30 \\
RPATRI2009 & 183 & 0 & 70452269 & 753346,86 & 5279476,11 \\
RPATRI2010 & 179 & 1060 & 90339344 & 970300,34 & 6792390,81 \\
RSERV2006 & 154 & 74 & 7776218 & 550874,19 & 985114,82 \\
RSERV2007 & 145 & 10 & 5608442 & 522484,42 & 784186,64 \\
\hline & & & & & \\
\hline
\end{tabular}




\section{Tabela 1 (continuação)}

\begin{tabular}{cccccc}
\hline Variável & Observações & Mínimo & Máximo & Média & Desvio Padrão \\
\hline RSERV2008 & 136 & 20 & 5552031 & 508617,34 & 942610,79 \\
RSERV2009 & 128 & 12 & 8861681 & 529599,35 & 1100293,39 \\
RSERV2010 & 113 & 5 & 16977518 & 706340,00 & 1924905,81 \\
RTRANSCO2006 & 184 & 5518135 & 1200818714 & 25720832,26 & 89858873,91 \\
RTRANSCO2007 & 181 & 6086405 & 1510109447 & 30112016,54 & 113177337,87 \\
RTRANSCO2008 & 177 & 7938954 & 1711095306 & 38255400,00 & 130324874,75 \\
RTRANSCO2009 & 184 & 8021476 & 1578110742 & 38533321,18 & 118718818,25 \\
RTRANSCO2010 & 180 & 9275555 & 1972343583 & 44792559,11 & 149050007,28 \\
OURECO2006 & 183 & 2601 & 53720987 & 623646,65 & 4119052,32 \\
OURECO2007 & 181 & 1235 & 69492922 & 799661,05 & 5278618,08 \\
OURECO2008 & 177 & 1281 & 180949591 & 1564754,50 & 13622670,94 \\
OURECO2009 & 184 & 0 & 96017131 & 920166,95 & 7099297,54 \\
OURECO2010 & 178 & 0 & 152692468 & 1377349,81 & 11485044,58 \\
RCAPI2006 & 177 & 648 & 28351816 & 2093420,19 & 3215940,40 \\
RCAPI2007 & 164 & 8000 & 27293811 & 1554416,61 & 2900778,06 \\
RCAPI2008 & 167 & 1072 & 101578156 & 2956981,25 & 8400390,72 \\
RCAPI2009 & 175 & 4500 & 118387272 & 2562964,97 & 9162043,81 \\
RCAPI2010 & 168 & 1914 & 109441405 & 3592253,84 & 8681837,95 \\
\hline
\end{tabular}

Importa, contudo, lembrar que, para Blaikie (2000), o desenho eleito é um dos mais complexos porque a inclusão de um período de análise tão longo poderá trazer alterações na coleta dos dados, tornando-os, deste modo, incomparáveis. Foi este o caso em razão das alterações de cálculo e/ou porque os indicadores não estavam disponíveis.

Conseguiu-se, no entanto, através dos anuários estatísticos produzidos pelo Instituto de Pesquisa e Estratégia Econômica do Ceará, coletar os dados da variável dependente e variáveis independentes. A variável dependente é o investimento ([INVES] que reporta à aquisição de instalações, equipamentos e material permanente, entre outros) realizado por cada um dos governos locais e cujo indicador se encontra inscrito na conta das finanças dos municípios e, em concreto, na despesa orçamentária empenhada e, dentro desta, nas despesas de capital. Esta escolha dá-se porque a distribuição dos orçamentos é parte central da teoria do equilíbrio pontuado (Jordan, 2003) e, no caso, é o indicador de referência.

Anteriormente afirmou-se que seria igualmente importante descrever a relação entre receita orçamentária na sua relação com a decisão para o investimento. Neste caso em concreto, verifica-se que, para True et al. (2007), os orçamentos variam de acordo com fatores quer endógenos, quer exógenos. E esses fatores podem ser captados através da receita orçamentária (são aqueles previstos na Lei Orçamentária Anual). Esta receita inclui os indicadores que captam exatamente estas disposições, porquanto delas dependem: as receitas correntes [que incluem a(s) receita(s) tributária(s) (RTRIBU), receitas de contribuições (RCONT), receita patrimonial (RPATRI), receita de serviços (RSERV), transferências correntes (RTRANSCO) e outras receitas correntes (OURECO)] e as receitas de capital 
[(RCAPI) que se constitui dos recursos financeiros que resultam da constituição de dívidas, da conversão em espécie, de bens e direitos, e das transferências de capital para gastos com despesa de capital]. Na sua essência, procurou-se, com estas variáveis independentes, atestar qual delas melhor explica os investimentos realizados no período considerado. Verificando a Tabela 1, constata-se que todos os indicadores aumentaram entre 2006 e 2010, exceto as receitas patrimoniais que são mais significativas em 2007 e outras receitas correntes que atingem o seu maior valor em 2008. Por outro lado, também se observa uma grande disparidade entre os valores mínimos e máximos verificados em todos os indicadores e anos. Essa razão se deve à grande concentração de população em determinadas áreas, o que faz com que o investimento seja maior nessas localidades e, em consequência, também as receitas com origem na tributação aumentam por conta do maior número de contribuintes.

\section{Ferramentas estatísticas utilizadas}

Para que possamos responder à questão de partida e ir de encontro aos objetivos de estudo propostos, fez-se, em um primeiro momento, a utilização da estatística descritiva (Bryman, 2004). Para o efeito, calculou-se a variação de um ano para o outro dos valores de investimento realizados pelos vários governos locais. Com esta ação, tentou-se descrever se a variação dos orçamentos segue a tendência leptocúrtica descrita anteriormente. Nesta fase é de primordial importância balizar o que pode ser denominado de pontuações. Neste caso em concreto, adotou-se o princípio de Jordan (2003) para quem toda a alteração de decréscimo que apresente $25 \%$ ou mais e toda a alteração positiva de $35 \%$ ou mais de variação de um ano para o outro seja considerada como pontuação.

Já em uma segunda fase, procurar-se-á atestar da regularidade entre o investimento realizado e a possível influência das receitas que acima enunciamos. Para o efeito, elegeu-se a análise de regressão que dará a relação entre a(s) variável(eis) independente(s) e a variável dependente através do $\mathrm{R}^{2}$ que, quanto mais se aproximar de 1, maior será essa mesma conexão. Por sua vez, será efetuado igualmente o teste do modelo proposto através da Análise de Variância (ANOVA), sendo que para o teste de Fisher será considerado o valor de $p<.05$. A análise atenta igualmente à relação entre as variáveis cuja robustez será dada pelo $T$-Student, que também exige que $p<.05$. Se por ventura os valores de $p$ estiverem abaixo do nível de significância $(p<.05)$, rejeita-se a hipótese nula e aceita-se a existência de diferenças. Por fim, a linearidade foi considerada através do teste de Durbin-Watson, no qual a distribuição de resíduos deverá cumprir a seguinte disposição: $1.5<p<2.5$ - e se tal se vier a verificar, o que aconteceu para todos os anos considerados, fica-se com total certeza da robustez dos dados.

\section{Resultados e Discussão}

Esta seção inicia-se pela descrição da evolução do investimento nos 184 governos locais cearenses entre os anos de 2006 e 2010. Verifica-se que em 2006 o investimento rondou os R \$711.017.968, sendo que, em 2007, registrou os $\mathrm{R} \$ 648.127 .912$, ou seja, o investimento diminuiu, perfazendo um total de pontuações negativas de 49.7\% - ver Tabela 2. Contudo, de 2007 para 2008, esse investimento aumentou para $\mathrm{R} \$ 1.045 .311 .279$, o que mostra que existiu uma grande variação entre orçamentos e que se pode chamar de pontuações. As pontuações positivas alcançaram os $65.2 \%$ do total das variações no investimento. Já para o ano de 2009, a tendência verificada no ano anterior não se manteve, porquanto o investimento decresceu (para $\mathrm{R} \$$ 943.354.332), e mesmo que a maioria das variações tenha sido do tipo normal (40.4\%), tal fato apenas aconteceu neste ano. Por fim, e já para o ano de 2010, verifica-se que o investimento voltou a aumentar (para $\mathrm{R} \$ 1.239 .328 .506$ ) e, naturalmente, que as pontuações positivas foram em maior número $(n=111)$ do que as outras $(n=73$ no somatório entre pontuações negativas com a distribuição dita normal). Em uma média dos anos considerados no intervalo de análise, apurou-se que o investimento aumentou, logo as pontuações positivas foram as mais frequentes $(n=302$, correspondendo a $41.6 \%$ do total), contra as pontuações negativas, que tiveram a sua maior expressão nos anos de 2006-2007 e 2008-2009. Por fim, a distribuição de tipo normal foi a menos frequente, mas mesmo assim próxima dos valores absolutos registrados nas pontuações negativas. Face a estes dados, 
confirma-se a hipótese do trabalho, isto é, verifica-se que existe de fato uma relação normal na distribuição dos orçamentos dos governos locais cearenses alterada por grandes variações.

Tabela 2

Variação do Investimento nos 184 Municípios do Estado do Ceará, Brasil

\begin{tabular}{lcccccccccc}
\hline Período & \multicolumn{2}{c}{$\mathbf{2 0 0 6 - 2 0 0 7}$} & \multicolumn{2}{c}{$\mathbf{2 0 0 7 - 2 0 0 8}$} & \multicolumn{2}{c}{$\mathbf{2 0 0 8 - 2 0 0 9}$} & \multicolumn{2}{c}{$\mathbf{2 0 0 9 - 2 0 1 0}$} & \multicolumn{2}{c}{$\mathbf{2 0 0 6 - 2 0 1 0}$} \\
\hline Tipo distribuição & $\mathbf{N}$ & $\mathbf{\%}$ & $\mathbf{N}$ & $\boldsymbol{\%}$ & $\mathbf{N}$ & $\mathbf{\%}$ & $\mathbf{N}$ & $\boldsymbol{\%}$ & $\mathbf{N}$ & $\boldsymbol{\%}$ \\
\hline Pontuações positivas & 34 & 18.6 & 118 & 65.2 & 39 & 22 & 111 & 60.3 & 302 & 41.6 \\
Pontuações negativas & 91 & 49.7 & 45 & 24.9 & 67 & 37.6 & 15 & 8.2 & 218 & 30 \\
Distribuição normal & 58 & 31.7 & 18 & 9.9 & 72 & 40.4 & 58 & 31.5 & 206 & 28.4 \\
Total & 183 & 100 & 181 & 100 & 178 & 100 & 184 & 100 & 726 & 100 \\
\hline
\end{tabular}

Face ao que foi apresentado, podemos concluir que as distribuições dos orçamentos nos governos locais do Estado do Ceará no Brasil não seguem sempre uma tendência incremental, ou seja, as decisões mostram inclusive grandes disparidades e inconstância de um ano para o outro. Mesmo sendo esta constância reduzida, os resultados agora alcançados corroboram os resultados avançados por Jones e Baumgartner (2005), Jones et al. (2003), Jordan (2003) e John e Margetts (2003).

Tais resultados não são de todo inesperados porque se o investimento no Estado do Ceará quadruplicou face aos restantes Estados Brasileiros, espera-se que as pontuações sejam maioritariamente do tipo positivo. Aliás, como refere Jordan (2003), quando existe a tomada de posse por parte dos prefeitos, é esperado que os gastos orçamentais aumentem, uma vez que urge cumprir as promessas eleitorais que implicarão necessariamente maiores gastos. Inversamente, afirma a autora que as pontuações negativas são mais frequentes quando a situação econômico-financeira é desfavorável. Não se verifica, contudo, esta situação no caso em análise, porque a conjuntura tem sido bastante favorável nos últimos anos para o Brasil, no seu todo, e para o Ceará, em especial. Contudo, mesmo considerando a evolução econômica constatada, em pelo menos dois anos (2007 e 2009) as pontuações negativas foram maiores do que as pontuações positivas. De realçar que, no ano de 2009, a distribuição dita normal foi aquela que prevaleceu ficando, deste modo, por explicar o decréscimo para o intervalo de 20062007. Devemos, no entanto, notar que a maior subida no investimento surge no ano de 2008, o que acaba por coincidir com o ano de eleições autárquicas. E, por motivos de reeleição, os políticos em atividade não vão arriscar cortar a oferta ou qualidade dos serviços públicos sob pena de verem frustrada a continuidade no cargo.

Considerando o segundo objetivo de pesquisa, aquele em que se pretende descrever a regularidade das rubricas que estão inclusas na receita orçamentária e que melhor se relacionam com o investimento efetuado, observa-se, pela Tabela 3, que todos os modelos são explicados em elevado grau pelas variáveis independentes. Destacam-se aqui as receitas de transferência correntes e receitas de capital; em todos os modelos se observa que $\mathrm{p}<.05$ Pontualmente, as receitas tributárias surgem como variável explicativa no nível de investimento (anos de 2006, 2008 e 2010), mas são as duas primeiras aquelas que prevalecem e cuja constância é total. Com estes resultados, verifica-se que não são as receitas cobradas a variável que prediz as alterações dos investimentos. As receitas tendem a seguir uma tendência mais constante, logo se mostram incapazes de contribuir marcadamente para a alteração dos investimentos realizados. Como demonstrado na análise, os investimentos dependem mais das receitas de transferência correntes e de capital. A mesma incapacidade é verificada em relação às outras variáveis, razão pela qual não são consideradas na explanação dos resultados. 
Tabela 3

Análise de Regressão de Tipo Stepwise, Fazendo Uso da Receita como Previsores do Investimento

\begin{tabular}{|c|c|c|c|c|c|c|c|c|c|c|}
\hline \multirow[b]{2}{*}{ Variável } & \multicolumn{2}{|c|}{$\begin{array}{c}\text { Modelo } 1 \\
(* * 2006)\end{array}$} & \multicolumn{2}{|c|}{$\begin{array}{c}\text { Modelo } 2 \\
(* * 2007)\end{array}$} & \multicolumn{2}{|c|}{$\begin{array}{c}\text { Modelo } 3 \\
(* * 2008)\end{array}$} & \multicolumn{2}{|c|}{$\begin{array}{c}\text { Modelo } 4 \\
(* * 2009)\end{array}$} & \multicolumn{2}{|c|}{$\begin{array}{l}\text { Modelo } 5 \\
(* * 2010)\end{array}$} \\
\hline & Coefi. & Esta.-t & Coefi. & Esta.-t & Coefi. & Esta. $-t$ & Coefi. & Esta.-t & Coefi. & Esta.-t \\
\hline (Constante) & .722 & -.357 & .001 & -3.434 & .084 & -1.748 & .006 & -2.827 & .271 & 1.108 \\
\hline RTRIBU & $.000^{*}$ & -5.375 & .219 & -1.240 & $.000 *$ & -4.693 & .161 & -1.415 & $.000 *$ & 5.661 \\
\hline RCONT & .749 & -.321 & .082 & -1.764 & .003 & 3.077 & .837 & -.207 & .117 & 1.583 \\
\hline RPATRI & $.000^{*}$ & 4.015 & .082 & -1.764 & .520 & -.646 & .863 & -.173 & $.019 *$ & -2.390 \\
\hline RSERV & .206 & 1.275 & .704 & -.381 & .774 & -.289 & .076 & 1.798 & .342 & -.956 \\
\hline RTRANSCO & $.050^{*}$ & 1.995 & $.000 *$ & 12.862 & $.000^{*}$ & 6.276 & $.000 *$ & 14.052 & $.000 *$ & 7.796 \\
\hline OURECO & $.001 *$ & 3.643 & $.001 *$ & -3.343 & .410 & -.828 & .565 & -.578 & .631 & -.483 \\
\hline RCAPI & $.000 *$ & 16.559 & $.000 *$ & 9.260 & $.000 *$ & 6.408 & $.000 *$ & 8.807 & $.000 *$ & 6.793 \\
\hline $\mathrm{R}$ & \multicolumn{2}{|c|}{.988} & \multicolumn{2}{|c|}{.996} & \multicolumn{2}{|c|}{.990} & \multicolumn{2}{|c|}{.997} & \multicolumn{2}{|c|}{.998} \\
\hline $\mathrm{R}^{2}$ & \multicolumn{2}{|c|}{.975} & \multicolumn{2}{|c|}{.992} & \multicolumn{2}{|c|}{.980} & \multicolumn{2}{|c|}{.994} & \multicolumn{2}{|c|}{.995} \\
\hline $\mathrm{R}^{2}$ ajustado & \multicolumn{2}{|c|}{.974} & \multicolumn{2}{|c|}{.922} & \multicolumn{2}{|c|}{.979} & \multicolumn{2}{|c|}{.994} & \multicolumn{2}{|c|}{.995} \\
\hline Mudança de F & \multicolumn{2}{|c|}{$575.305^{*}$} & \multicolumn{2}{|c|}{$3312.551^{*}$} & \multicolumn{2}{|c|}{$1022.229 *$} & \multicolumn{2}{|c|}{$6798.976^{*}$} & \multicolumn{2}{|c|}{$4059.983 *$} \\
\hline Graus liberdade & \multicolumn{2}{|c|}{78} & \multicolumn{2}{|c|}{84} & \multicolumn{2}{|c|}{86} & \multicolumn{2}{|c|}{84} & \multicolumn{2}{|c|}{83} \\
\hline N. observações & \multicolumn{2}{|c|}{175} & \multicolumn{2}{|c|}{164} & \multicolumn{2}{|c|}{105} & \multicolumn{2}{|c|}{175} & \multicolumn{2}{|c|}{167} \\
\hline
\end{tabular}

Nota. * significância <.5; ** variável dependente: investimento.

Face a estes resultados, pode-se afirmar que o investimento que tem sido realizado está dependente das transferências que a União faz para os governos locais do Estado do Ceará. Ao mesmo tempo, observa-se que são as receitas de capital, aquelas que se firmam na constituição de dívidas, entre outras, as que prevalecem. No final, é o endividamento de cada autarquia, a par das transferências que realizam, que constituem a capacidade financeira dos governos locais para continuadamente prestarem os serviços públicos que lhes estão atribuídos. Paradigmático desta realidade é o fato das receitas de serviços não se mostrarem, em nenhum dos anos considerados, capazes de fazer valer o investimento realizado.

\section{Conclusões e Futuras Investigações}

Esta investigação descreveu um fenômeno em particular, o da decisão para o investimento nos governos locais. A análise recorreu à teoria do equilíbrio pontuado, que defende que a distribuição dos orçamentos segue uma linha incremental em virtude da estabilidade existente na produção de bens e prestação de serviços públicos (Jordan, 2003). Segundo as premissas desta teoria, essa tranquilidade é interrompida, por vezes, com alterações drásticas na distribuição do dinheiro público.

Com base na perspectiva dedutiva, para que pudéssemos testar a teoria em apreço, foram escolhidos os 184 governos locais do Estado do Ceará para realizar o estudo. No caso em apreço, conclui-se que a distribuição dos orçamentos não é incremental, uma vez que as pontuações, quer positivas, quer negativas, vão-se sucedendo, confirmando a hipótese formulada: a distribuição dos orçamentos dos governos locais segue uma tendência normal, pontualmente alterada por grandes variações. 
Particular preocupação surge com a grande variação que se observa nomeadamente quando as pontuações negativas são quase tão frequentes como as de tipo normal. A instabilidade é, como foi afirmado, elevada e não existe o fator econômico que o possa explicar, uma vez que o Brasil se encontrava neste período em franca ascendência econômica, mesmo em contraciclo em comparação com a esmagadora maioria dos remanescentes países desenvolvidos.

Se nos países da Organização para a Cooperação e Desenvolvimento Econômico os orçamentos se encontram fortemente pressionados para a diminuição do nível e grau de investimentos públicos (Pollitt, 2012), tal fato resulta do grau de endividamento dos vários governos, sejam eles nacionais ou locais (Silvestre, 2012). E é aqui que despontam as implicações para os resultados deste estudo, que em um segundo momento mostram que os investimentos dos governos locais cearenses estão fortemente relacionados com as transferências que vêm da União e também da capacidade e nível de endividamento de cada autarquia.

Face a estas condições, dever-se-á equacionar até que nível e grau o endividamento pode ser realizado em virtude da escassez cada vez maior do dinheiro público e que, por sua vez, estão dependentes do comportamento da economia no seu todo. Neste caso em particular, é público que a economia brasileira não cresceu tanto quanto seria de esperar e isso poderá ter implicações nas transferências da União para os governos locais. Como a carência de serviços públicos em quantidade e qualidade - como escolas ou hospitais - ainda se verifica, é então importante que se defina o grau e nível de endividamento sob pena de serem adotadas medidas para aumentar as receitas tal qual acontece noutros países.

Assim, outros modos alternativos poderão ser equacionados, como já acontece com as Parcerias Público-Privadas para os aeroportos e, por exemplo, onde o investimento foi assegurado estando a concessionária obrigada a cumprir um conjunto de requisitos sob pena de ver o contrato rescindido. Como o desenvolvimento econômico leva a que as populações exijam mais e melhores serviços públicos (Birkland, 2011), as Parcerias Público-Privadas passam a ser uma alternativa ao crescente endividamento dos governos locais, tendo as necessárias cautelas no estabelecimento dos contratos firmados (Silvestre \& Araújo, 2012).

Futuras investigações são, contudo, necessárias para dar maior robustez a estes resultados. Em primeiro lugar, em relação ao próprio Estado do Ceará, dever-se-á estender a análise para uma série temporal mais alargada, de modo a atestar em definitivo uma tendência. Em segundo lugar, é importante ampliar esta análise a outros Estados brasileiros para se tentar perceber se os resultados deste estudo são uma característica cearense ou se é uma realidade extensível a outros estados. Em seguida, é importante que se focalize a análise, já não única e exclusivamente na tomada de decisão para a afetação dos recursos públicos, mas também na própria ação dos líderes políticos e na percepção que têm acerca desta questão (Blomquist, 2007). Por fim, é importante atestar do grau de endividamento dos governos locais, principalmente para que se possa perceber quais as responsabilidades assumidas e, hipoteticamente, para que se inicie ou continue a discussão acerca da necessidade da utilização de modos alternativos na produção de bens e prestação de serviços públicos.

\section{Agradecimentos}

Agradecemos ao CNPq pelo apoio concedido para a realização deste trabalho (processo n ${ }^{\circ}$ 471818/2013-5).

\section{Referências}

Berry, F., \& Berry, W. (2007). Innovation and diffusion models in policy research. In P. Sabatier (Ed.), Theories of the policy process (2nd ed., pp. 223-260). Colorado: Westview Press. 
Birkland, T. (2011). An introduction to the policy process - Theories, concepts, and models of public policy making (3rd ed.). London: M. E. Sharp.

Blaikie, N. (2000). Designing social research - The logic of anticipation. Cambridge: Polity.

Blomquist, W. (2007). The policy process and large- $n$ comparative studies. In P. Sabatier (Ed.), Theories of the policy process (2nd ed., pp. 261-289). Colorado: Westview Press.

Bryman, A. (2004). Social research methods (2nd ed.). Oxford: Oxford University Press.

Camões, P. S. (2012). O design de investigação. In H. C. Silvestre \& J. F. Araújo (Eds.), Metodologia para a investigação social (pp. 103-119). Lisboa: Escolar Editora.

Denhardt, R. (2000). Theories of public administration (3rd ed.). London: Harcourt Brace \& Company.

Instituto de Pesquisa e Estratégia Econômica do Ceará. (2006). Anuário estatístico do Ceará 2006. Recuperado de http://www2.ipece.ce.gov.br/publicacoes/anuario/anuario2006/index.htm

Instituto de Pesquisa e Estratégia Econômica do Ceará. (2007). Anuário estatístico do Ceará 2007. Recuperado de http://www2.ipece.ce.gov.br/publicacoes/anuario/anuario2007/index.htm

Instituto de Pesquisa e Estratégia Econômica do Ceará. (2008). Anuário estatístico do Ceará 2008. Recuperado de http://www2.ipece.ce.gov.br/publicacoes/anuario/anuario2008/index.htm

Instituto de Pesquisa e Estratégia Econômica do Ceará. (2009). Anuário estatístico do Ceará 2009. Recuperado de http://www2.ipece.ce.gov.br/publicacoes/anuario/anuario2009/index.htm

Instituto de Pesquisa e Estratégia Econômica do Ceará. (2010). Anuário estatístico do Ceará 2010. Recuperado de http://www2.ipece.ce.gov.br/publicacoes/anuario/anuario2010/index.htm

John, P., \& Margetts, H. (2003). Policy punctuations in the UK: fluctuations and equilibria in central government expenditure since 1951. Public Administration, 81(3), 411-432. doi: 10.1111/14679299.00354

Jones, B., \& Baumgartner, F. R. (2005). A model of choice for public policy. Journal of Public Administration Research and Theory, 15(3), 325-351. doi: 10.1093/jopart/mui018

Jones, B., Sulkin, T., \& Larsen, H. (2003). Policy punctuations in American political institutions. American Political Science Review, 97(1), 151-169. doi: 10.1017/S0003055403000583

Jordan, M. (2003). Punctuations and agendas: a new look at local government budget expenditures. Journal of Politics Analysis and Management, 22(3), 345-360. doi: 10.1002/pam.10136

Pollitt, C. (2012). New perspectives on public services - Place and technology. Oxford: Oxford University Press.

Robinson, S., Caver, F., Meier, K. J., \& O'Toole, L. (2004, April). Explaining policy punctuations: a multivariate model of the punctuated equilibrium theory of public agency budgets. Encontro da Associação de Ciência Política Norte-Americana, Chicago, IL, EUA.

Sabatier, P. (2007). The need for better theories. In P. Sabatier (Ed.), Theories of the policy process (2nd ed., pp. 3-17). Colorado: Westview Press.

Silvestre, H. C. (2012). Public-private partnership and corporate public sector organizations: alternative ways to increase social performance in the Portuguese water sector? Utilities Policy, 22, 41-49. doi: 10.1016/j.jup.2012.01.002 
Silvestre, H. C., \& Araújo, J. F. F. E. de (2012). Public private partnership/private finance initiative in Portugal: theory, practice and results. Public Performance \& Management Review, 36(2), 316339. doi: 10.2753/PMR1530-9576360208

Simon, H. (1982). Models of bounded rationality (Vol. 2). Massachusetts: MIT Press.

True, J., Jones, B., \& Baumgartner, F. (2007). Punctuated equilibrium theory: explaining stability and change in public policymaking. In P. Sabatier (Eds.), Theories of the policy process (2nd ed., pp. 155-187). Colorado: Westview Press.

Yin, R. (2009). Case study research, design and methods (4th ed.). London: Sage.

\section{Dados dos Autores}

Hugo Consciência Silvestre

Av. da Abolição, 3, Centro, Campus da Liberdade, 62790-000, Redenção, CE, Brasil. E-mail: hmcsilvestre@ gmail.com

Joaquim Filipe Ferraz Esteves de Araújo

Campus de Gualtar, 4710-057, Braga, Portugal. E-mail: jfilipe @eeg.uminho.pt 